\title{
Electrocardiographic Changes in Chronic Obstructive Pulmonary Disease - An observational study from North-East of India
}

\author{
Atanu Pal', Arabinda Das ${ }^{2}$, jibeswar Thakuria ${ }^{3}$ \\ ${ }^{1}$ Department of Rheumatology and Nephrology, Institute of Post Graduate Medical Education \& Research, 242, AJC Bose \\ Road, Kolkata, West Bengal, India. \\ 2Department of Statistics, Acharya Prafulla Chandra College, New Barrackpore, Kolkata, West Bengal, India. \\ ${ }^{3}$ Department of Medicine, Fakhruddin Ali Ahmed Medical College, Barpeta-Hospital-Jania Rd, JotiGaon, Assam, India. \\ DOI: https://doi.org/10.24321/0019.5138.202005
}

I $\quad \mathbf{N} \quad \mathbf{F} \quad \mathbf{O}$

Corresponding Author:

Arabinda Das, Department of Statistics, Acharya Prafulla Chandra College, New Barrackpore, Kolkata, West Bengal, India.

E-mail Id:

arabinda@apccollege.ac.in

Orcid Id:

https://orcid.org/0000-0002-4025-1926

How to cite this article:

Pal A, Das A, Thakuria J. Electrocardiographic Changes in Chronic Obstructive Pulmonary Disease - An observational study from NorthEast of India. J Commun Dis 2020; 52(1): 32-37.

Date of Submission: 2020-03-08

Date of Acceptance: 2020-04-03
$\begin{array}{llllllll}\mathbf{A} & \mathbf{B} & \mathbf{S} & \mathbf{T} & \mathbf{R} & \mathbf{A} & \mathbf{C} & \mathbf{T}\end{array}$

Chronic obstructive pulmonary disease has got significant cardiovascular morbidity and mortality. The adverse cardiac effect can be picked up early by Electrocardiography (ECG) and echocardiography. Here, in this study, we tried to find out the different ECG changes in COPD and its correlation with disease duration, severity and other factors. We conducted a cross-sectional observational study in the Assam Medical College, Dibrugarh for a span of one year where 234 spirometrically confirmed COPD patients had undergone ECG. Most of the patients belonged to GOLD stage III (40\%) and P-pulmonale was the most common ECG abnormality (63.3\%). Other ECG findings were right axis deviation, right ventricular hypertrophy, incomplete right bundle branch block, S1Q3T3, S1Q3 pattern and Atrial Fibrillation (AF), having an increasing trend of abnormalities with the severity of GOLD stage. Increased incidence of AF is due to severity and longer duration of the disease. AF and right axis deviation occur more in smokers. Low voltage ECG is a nonspecific finding. The ECG changes were well correlated with disease severity and duration.

Keywords: COPD, ECG, AF, p-Pulmonale, GOLD

\section{Introduction}

Chronic Obstructive Pulmonary Disease (COPD), as the name suggests, there is chronic airflow obstruction in the lung. Smoking is the most important risk factor for its development. COPD is currently the fourth leading cause of death in the world ${ }^{1}$ but is projected to be the third leading cause of death by 2020 . This disease causes significant changes in the cardiac function, including that of the right and left ventricles as well as the pulmonary blood vessels. ${ }^{2}$ Pulmonary vascular disease associated with COPD increases morbidity and worsens survival. ${ }^{3}$ The spectrum of cardiovascular disease includes Right Ventricular (RV) dysfunction, Pulmonary Hypertension (PH), Coronary Artery Disease (CAD) and arrhythmias. ${ }^{4}$ Patients with COPD carry an increased risk of mortality due to arrhythmia, myocardial infarction, or congestive heart failure compared with those who do not. ${ }^{5}$ A study with large number of patients revealed increased cardiovascular mortality, particularly in patients younger than 65 years with COPD. ${ }^{6}$ 
Electrocardiography and echocardiography are the two modalities which can detect the arrhythmia, pulmonary hypertension and the right ventricular dysfunction so these can be useful in initiation of early treatment and to prolong the survival and improvement of the quality of life of the COPD patients. Here, we studied the various electrocardiographic changes among the COPD patients in the north-eastern part of India and its association with the etiology, demography, duration and severity of COPD where there is paucity of data regarding COPD and its complications.

\section{Material and Method}

\section{Study Design}

The study is a cross sectional and observational study. It was conducted among the patients attending the Respiratory Clinic and Medicine OPD of Assam Medical College and Hospital, Dibrugarh, Assam throughout a period of one year.

\section{Participants and Recruitment}

The study populations were all COPD patients attending Respiratory Clinic and Medicine OPD of Assam Medical College and Hospital who were available during data collection period. Two hundred fifty adult patients including both gender who fulfilled the inclusion criteria were taken for the study. The patients were recruited sequentially whenever they obeyed the inclusion and exclusion criteria. The Ethics Committee of the Assam Medical College and Hospital, Assam, approved the study. A written wellinformed consent was obtained from all participants and the study was performed according to the Declaration of Helsinki, 1975.

\section{Inclusion Criteria}

All patients above 40 years of age with or without smoking history of more than 20 pack years with or without chronic cough and or sputum production with FEV1/FVC $<0.7$ and post-bronchodilator $\mathrm{FEV}_{1}$ less than $80 \%$ of the predicted value with an increase in $\mathrm{FEV}_{1}$ less than $200 \mathrm{ml}$ or less than $12 \%$ of baseline value 20 minutes after 2 puffs of inhaled salbutamol given by a metered dose inhaler through a spacer.

\section{Exclusion Criteria}

The patients with the following diseases were excluded from the study:1) Tuberculosis, 2) Bronchial asthma, 3) Interstitial lung disease, 4) Previous lung surgery, 5) Coronary artery disease, 6) Diabetes Mellitus, 7) Chronic alcoholism, 8) Uremia, 9) Hypertension, 10) Thyroid disorder.

\section{Methods}

After fulfilling the inclusion and exclusion criteria for the study all the patients were thoroughly examined. The examinations were done by trained technician employed in the department of cardiology. Oriented about the objectives and purpose of the study, the technicians took informed verbal and written consent prior to examination and data collection. Then, the participants were given a structured questionnaire to assess COPD related and different socioeconomic and demographical variables. Body mass index (BMI) was computed from participants' height and weight measured with validated tape meter and weight scale at standing position. Dynamic pulmonary function test was carried out todiagnose and grade severity of COPD based on post-bronchodilatorresult of forced expiratory volume in one second (FEV1), percent predicted, forced vital capacity (FVC) and (FEV1/FVC) ratio as per the guideline of Global Initiative for Chronic Obstructive Lung Disease (GOLD) ${ }^{1}$ by using dry digital spirometry (Care Fusion, Germany). Finally every participant underwent ECG investigation using standard 12-lead supine resting ECG (NIHONKOHDEN Cardiofax S) with machine calibrated on $1 \mathrm{mV}$ for a $10 \mathrm{~mm}$ $(0.1 \mathrm{mV} / \mathrm{mm})$ at speed of $25 \mathrm{~mm} / \mathrm{s}$, where each small box and large box represents $0.04 \mathrm{~s}$ and $0.2 \mathrm{~s}$ respectively.

\section{Statistical Analysis}

Continuous variables were described with means and standard deviations of the variables and categorical variables as numbers and percentages. Differences in baseline characteristics were examined with one way ANOVA or chi-square test, when appropriate. Binary outcome variableswere analyzed with multivariate logistic regression to compute Odds Ratios (OR). Unadjusted and adjusted Odd Ratios (OR) with 95\% Confidence Interval (Cl) were calculated for each diagnostic of ECG to evaluate the risk developed in each GOLD stage. Adjusted OR were calculated with adjusted to age, gender and BMI. ORs with $95 \%$ confidence interval were also used to find the association of duration of COPD and smoking status with the different ECG abnormalities. Chi-square test for trend was performed to find possible association between different characteristics and different measures of ECG abnormalities. p-value $<0.01$ was considered to be statistically significant. All the statistical analysis were performed in R 3.4 statistical software.

\section{Result and Observation}

Two hundred fifty patients were screened during the course of the study, out of which two hundred thirty four spirometrically confirmed COPD patients were included for the study. The ECG of all the patients were done following the method described in the method sub-section and the results were recorded.

The participants were divided into four GOLD stages based on FEV1\% predicted and most of the participants belonged to the GOLD Stage III (40\%) and least were in the GOLD Stage I (5\%). The characteristics of the participants under different 
categories of GOLD are presented in Table 1. This showed no significant difference in average age of participants under different GOLD categories. Among the participants, $63 \%$ were male. The average BMI and duration of illness of the participants for different categories of GOLD were not significant. Moreover, gender and biomass exposure were not significantly related to GOLD. Table 2 presents the occurrence of all possible ECG changes in the selected COLD population. Out of 234 patients studied 206 patients $(88.03 \%)$ had changes in the ECG. P-Pulmonale was the commonest ECG abnormality (63.33\%) and other findings are shown in Table 2. Table 3, revealed the adjusted and unadjusted OR of P-pulmonale, right axis deviation, $\mathrm{RVH}$, RBBB, AF and Low voltage ECG under different stages of GOLD. The adjusted ORs of P-Pulmonale, right axis deviation, RVH, RBBB, AF and RVH ECGshowed a significant uniformly increasing trend of abnormality with the severity of GOLD. However, the result is not similar for low voltage ECG showing a mixed trend of developing low voltage ECG with severity of GOLD. Table 4, presents the adjusted and unadjusted ORs of different diagnostic of ECG abnormalities for duration of COPD. Except the adjusted ORs of RVH, all other diagnostics of ECG showed no significant trend of abnormality with severity of GOLD. Table 5, showed a significant trend of abnormality in AF and low-voltage ECG for smoking status with severity of GOLD. The right axis deviation and RBBB occur early, within 10 years of the disease.

Table I.Baseline characteristics of the study population stratified by severity of COPD according to the GOLD stage

\begin{tabular}{|c|c|c|c|c|c|c|}
\hline \multirow{2}{*}{ Characteristics } & & \multicolumn{4}{|c|}{ GOLD Stage } & \multirow[b]{2}{*}{ p-value } \\
\hline & & I & II & III & IV & \\
\hline Age (years, SD) & & $66.33(5.13)$ & $63.72(11.64)$ & $64.67(11.66)$ & $61.33(10.98)$ & 0.803 \\
\hline \multirow{2}{*}{ Gender } & Male & 12 & 51 & 54 & 27 & \multirow{2}{*}{0.144} \\
\hline & Female & 4 & 16 & 39 & 31 & \\
\hline Smoking (pack/ years) & & $27.67(5.86)$ & $25.72(17.54)$ & $22.88(23.17)$ & $15.47(19.63)$ & 0.492 \\
\hline FEV1 (\%pred, SD) & & $84.67(6.43)$ & $58.89(8.55)$ & $43.25(6.05)$ & $24.07(3.73)$ & 0.000 \\
\hline Duration of Illness (Years) & & $7.00(2.65)$ & $7.28(3.36)$ & $10.21(12.68)$ & $7.87(3.58)$ & 0.684 \\
\hline BMI & & $21.97(1.83)$ & $19.72(4.03)$ & $19.38(3.43)$ & 19.60 (3.99) & 0.729 \\
\hline \multirow{2}{*}{ Biomass Exposure } & No & 12 & 51 & 54 & 27 & \multirow{2}{*}{0.144} \\
\hline & Yes & 4 & 16 & 39 & 31 & \\
\hline
\end{tabular}

Table 2.ECG changes in COPD patients

\begin{tabular}{|c|c|c|}
\hline ECG changes & No. of patients & \% of patients \\
\hline P-Pulmonale (\%) & 148 & 53.25 \\
\hline Right Axis Deviation (\%) & 125 & 50 \\
\hline RVH ECG & 117 & 28.21 \\
\hline Incomplete RBBB (\%) & 66 & 28.21 \\
\hline Low voltage ECG (\%) & 66 & 20.09 \\
\hline AF (\%) & 47 & 20.09 \\
\hline S1S2S3 & 47 & 11.54 \\
\hline S1Q3 & 27 & \\
\hline
\end{tabular}

Table 3.Relationship of GOLD Stages with ECG Abnormalities

\begin{tabular}{|c|c|c|c|c|c|c|}
\hline \multirow{2}{*}{\multicolumn{2}{|c|}{ ECG Abnormality }} & \multicolumn{4}{c|}{ GOLD Stage } & \multirow{2}{*}{$\begin{array}{c}\text { Test for } \\
\text { trend }\end{array}$} \\
\cline { 2 - 8 } & I & II & III & IV & $>0.01$ \\
\hline $\begin{array}{c}\text { P-Pulmonale } \\
(\%)\end{array}$ & Unadjusted OR & 1 & $1.12(0.13,4.72)$ & $1.27(0.35,4.54)$ & $1.75(0.39,7.73)$ & $<0.01$ \\
\cline { 2 - 8 } & Adjusted OR & 1 & $1.67(0.54,7.28)$ & $2.43(0.65,9.03)$ & $3.14(0.65,15.19)$ & $<0.01$ \\
\hline $\begin{array}{c}\text { Rt. Axis } \\
\text { deviation (\%) }\end{array}$ & Unadjusted OR & 1 & $1.62(0.37,5.28)$ & $1.86(0.54,6.43)$ & $6.28(1.29,30.54)$ & $<0.01$ \\
\cline { 2 - 8 }
\end{tabular}




\begin{tabular}{|c|c|c|c|c|c|c|}
\hline \multirow{2}{*}{ S1S2S3 } & Unadjusted OR & 1 & $1.11(0.26,3.27)$ & $1.59(0.58,5.73)$ & $3.21(1.12,18.43)$ & $<0.01$ \\
\cline { 2 - 7 } & Adjusted OR & 1 & $2.32(1.06,13.92)$ & $4.15(1.07,19.63)$ & $10.23(2.42,84.31)$ & $<0.01$ \\
\hline \multirow{2}{*}{ S1Q3 } & Unadjusted OR & 1 & $1.02(0.17,2.23)$ & $1.35(0.44,4.85)$ & $2.36(1.02,8.32)$ & $<0.01$ \\
\cline { 2 - 7 } & Adjusted OR & 1 & $1.93(0.93,16.31)$ & $2.33(0.83,15.31)$ & $5.37(1.88,25.54)$ & $<0.01$ \\
\hline \multirow{2}{*}{$\begin{array}{c}\text { Incomplete } \\
\text { RBBB (\%) }\end{array}$} & Unadjusted OR & 1 & $1.78(0.28,7.12)$ & $2.50(0.56,11.23)$ & $3.33(0.67,16.74)$ & $<0.01$ \\
\cline { 2 - 7 } & Adjusted OR & 1 & $2.19(0.82,15.93)$ & $3.87(0.83,18.08)$ & $30.06(0.99,30.06)$ & $<0.01$ \\
\hline \multirow{2}{*}{ AF (\%) } & Unadjusted OR & 1 & $3.63(0.53,24.63)$ & $5.67(0.62,52.09)$ & $8.50(0.86,83.49)$ & $<0.01$ \\
\cline { 2 - 7 } & Adjusted OR & 1 & $1.26(0.37,8.81)$ & $2.50(0.48,13.09)$ & $8.26(1.23,55.55)$ & $<0.01$ \\
\hline \multirow{2}{*}{ RVH ECG } & Unadjusted OR & 1 & $3.81(1.67,23.74)$ & $11.20(2.08,60.04)$ & $52.00(6.42,421.3)$ & $<0.01$ \\
\cline { 2 - 7 } & Adjusted OR & 1 & $11.29(2.66,102.68)$ & $28.26(4.30,185.5)$ & $67.31(12.54,772.1)$ & $<0.01$ \\
\hline \multirow{2}{*}{$\begin{array}{c}\text { Low voltage } \\
\text { ECG (\%) }\end{array}$} & Unadjusted OR & 1 & $0.72(0.14,2.85)$ & $1.30(0.34,4.94)$ & $0.94(0.20,4.41)$ & $>0.01$ \\
\cline { 2 - 7 } & Adjusted OR & 1 & $1.18(0.41,6.07)$ & $2.40(0.56,10.23)$ & $1.40(0.25,7.90)$ & $>0.01$ \\
\hline
\end{tabular}

Table 4.Relationship of duration of COPD with ECG Abnormalities

\begin{tabular}{|c|c|c|c|c|c|c|}
\hline \multirow{2}{*}{\multicolumn{2}{|c|}{ ECG Abnormality }} & \multicolumn{4}{|c|}{ Duration (Years) } & \multirow{3}{*}{$\begin{array}{c}\text { Test for } \\
\text { Trend } \\
>0.01 \\
\end{array}$} \\
\hline & & \multirow{2}{*}{$\begin{array}{c}\mathbf{0 - 5} \\
1\end{array}$} & \multirow{2}{*}{$\begin{array}{c}\mathbf{0 6 - 1 1} \\
0.73(0.22,2.45)\end{array}$} & \multirow{2}{*}{$\begin{array}{c}12-15 \\
1.44(0.28,7.21)\end{array}$} & \multirow{2}{*}{$\begin{array}{c}>15 \\
1.08(0.08,14.07)\end{array}$} & \\
\hline P-Pulmonale & Unadjusted OR & & & & & \\
\hline & Adjusted OR & 1 & $0.85(0.25,3.17)$ & $0.95(0.17,5.27)$ & $0.74(0.05,10.69)$ & $>0.01$ \\
\hline \multirow{2}{*}{$\begin{array}{c}\text { Rt. Axis } \\
\text { deviation (\%) }\end{array}$} & Unadjusted OR & 1 & $1.26(0.38,4.20)$ & $1.78(0.36,8.81)$ & $1.34(0.10,17.28)$ & $>0.01$ \\
\hline & Adjusted OR & 1 & $1.22(0.33,4.45)$ & $2.42(0.44,13.42)$ & $1.81(0.11,29.18)$ & $>0.01$ \\
\hline \multirow{2}{*}{$\begin{array}{c}\text { Incomplete } \\
\text { RBBB (\%) }\end{array}$} & Unadjusted OR & 1 & $2.09(0.46,9.38)$ & $6.8(1.23,37.50)$ & $2.83(0.19,41.99)$ & $>0.01$ \\
\hline & Adjusted OR & 1 & $3.46(0.89,13.45)$ & $8.43(2.14,45,32)$ & $4.79(0.85,54.24)$ & $>0.01$ \\
\hline \multirow{2}{*}{$A F(\%)$} & Unadjusted OR & 1 & $0.63(0.14,2.77)$ & $2.5(0.52,11.89)$ & $1(0.08,11.93)$ & $>0.01$ \\
\hline & Adjusted OR & 1 & $0.33(0.06,1.78)$ & $8.7(1.13,66.97)$ & $3.08(0.15,64.57)$ & $>0.01$ \\
\hline \multirow{2}{*}{ RVH ECG } & Unadjusted OR & 1 & $0.78(0.24,2.56)$ & $0.83(0.19,3.64)$ & $1(0.11,8.56)$ & $<0.01$ \\
\hline & Adjusted OR & 1 & $0.72(0.21,2.42)$ & $1.88(0.39,9.03)$ & $2.19(0.16,29.51)$ & $<0.01$ \\
\hline \multirow{2}{*}{$\begin{array}{l}\text { Low voltage } \\
\text { ECG (\%) }\end{array}$} & Unadjusted OR & 1 & $0.46(0.12,1.78)$ & $0.69(0.14,3.49)$ & $1.86(0.21,16.18)$ & $<0.01$ \\
\hline & Adjusted OR & 1 & $0.64(0.15,2.76)$ & $0.6(0.10,3.50)$ & $4.48(0.31,65.56)$ & $>0.01$ \\
\hline
\end{tabular}

Table 5.Relationship of smoking status with ECG Abnormalities

\begin{tabular}{|c|c|c|c|c|c|}
\hline \multirow{2}{*}{ ECG Abnormality } & \multicolumn{4}{|c|}{ Smoking Status } & \multirow{2}{*}{$\begin{array}{c}\text { Test for } \\
\text { Trend }\end{array}$} \\
\cline { 2 - 6 } & No & $\mathbf{0 1 - 2 5}$ & $\mathbf{2 6 - 5 0}$ & $\mathbf{5 1 - 1 0 0}$ & $<0.01$ \\
\hline AF (\%) & 1 & $1.33(0.23,7.80)$ & $2.49(0.54,11.44)$ & $5.33(0.52,4.03)$ & $>0.01$ \\
\hline Rt Axis Deviation (\%) & 1 & $2.7(0.23,30.85)$ & $1.93(0.54,6.87)$ & $2.48(0.58,10.62)$ & $>0.01$ \\
\hline P-Pulmonale (\%) & 1 & $1.6(0.37,7.02)$ & $0.7(0.19,2.45)$ & $1.75(0.15,20.23)$ & $>0.01$ \\
\hline S1S2S3 & 1 & $1.36(0.28,6.68)$ & $0.59(0.11,3.06)$ & $1.25(0.10,15.49)$ & $>0.01$ \\
\hline S1Q3 & 1 & $1.33(0.23,7.80)$ & $0.84(0.15,4.76)$ & $1.78(0.13,23.40)$ & $>0.01$ \\
\hline Incomplete RBBB (\%) & 1 & $0.70(0.14,3.56)$ & $1.6(0.42,6.11)$ & $0.93(0.08,11.18)$ & $>0.01$ \\
\hline RVH ECG & 1 & $0.60(0.15,2.36)$ & $1.08(0.31,3.69)$ & $0.9(0.10,7.78)$ & $<0.01$ \\
\hline Low voltage ECG (\%) & 1 & $0.7(0.14,3.56)$ & $1.93(0.51,7.32)$ & 0 & \\
\hline
\end{tabular}

\section{Discussion}

The COPD is one of the most important causes of increasing morbidity and mortality worldwide. The diseases involving pulmonary vasculature due to COPD increase morbidityand worsen survival. ${ }^{7}$ In patients with mild to moderate 
COPD (FEV1, $>60 \%$ of predicted), cardiovascular events are the leading cause of hospitalization and the second leading cause of mortality. ${ }^{8}$ Among patients with Global Initiative for Chronic Obstructive Lung Disease (GOLD) stages 0 to 2 disease (i.e., FEV1 $>50 \%$ of predicted), cardiovascular disorders account for approximately $50 \%$ of all hospitalizations and nearly a third of all deaths. ${ }^{8}$ In more advanced disease, cardiovascular events account for $20 \%$ to $25 \%$ of all deaths in COPD. ${ }^{9}$ Similarly the different abnormalities of the heart in COPD with respect to ECG findings of our study are discussed below. In the present study, 144 patients (61.5\%) were male and 90 (38.5\%) were female. Several studies showed earlier that males are mostly affected (up to 90\%). ${ }^{10}$ But there was a higher trend of females getting involved in recent studies, especially in lower socioeconomic strata and in young age. ${ }^{11}$ The cause attributed to this was increasing smoking habit in young female and among the lower class of people. In our study, biomass exposure is most likely the cause of higher prevalence of female as it is the commonly used fuel in rural areas of this part of our country.Mean age of the patients in our study was 63.63 years which is similar to other studies where it was shown that as age increases the prevalence of COPD also increased especially above 55 years. ${ }^{6}$ In the present study, most of the patients belong to the GOLD Stage III (40\%) and this findings corroborate with the other studies performed in different part of the world $\mathrm{d}^{12,13}$ and indicates that most of the COPD patients present at this stage.

The incidence of P-pulmonale in different studies has been variable: $13.9 \%$ to $95 \%$, which might be due to the long follow-up and severe pulmonary disease. ${ }^{14,15,16,17}$ $\mathrm{P}$-pulmonale is well known as an indirect evidence of RVH. In the present study, when FEV1\% predicted decreases to $\leq 80 \%$ (i.e. GOLD Stage II), there is gradual increase in the percentage of patients with P-pulmonale, but mostly it becomes evident from GOLD Stage III. So there is an inverse relationship of FEV1\% predicted (direct relationship with GOLD Staging) with the P-pulmonale. So, more severe the COPD means more the chance of getting P-pulmonale and this data supports the previous works. ${ }^{18,19}$ The incidence of right axis deviation in patients with chronic P-pulmonale vary from 46 to 85 percent in different studies. ${ }^{20,21}$ The currentstudy also found that it occurs within 10 years of the disease and the incidence increases with severity of GOLD stages. It also appeared early as right axis deviation and had a uniformly increasing trend with the severity of GOLD stages. The other studies showed $60 \%$ to $75 \%$ of incidence of RVH, and it increases with the advances in GOLD stages. ${ }^{13,22}$ This study found an increasing trend for RBBB with the severity of GOLD stages which is similar to previousstudies. ${ }^{13,22}$ The previous studies had $5 \%$ to $41 \%$ low voltage ECG. ${ }^{13,23}$ In our study the low voltage ECG was not correlated with the severity of GOLD stages, it was a non-specific finding. S1Q3 pattern in ECG is as high as $90 \%$ specific for diagnosing RVH. S1Q3 patternwas noted in $48 \%$ of the patients with pathologically proven RVH in one study. ${ }^{23}$

Only $7.5 \%$ cases had AF in a study by Dharet et al. ${ }^{24}$ Increased number of patients with advanced disease in the present study responsible for increased percentage of AF. Buchet al. ${ }^{25}$ concluded in their study that reduced FEV1\% predicted is an independent predictor of new onset AF. Since AF, if untreated, causes high morbidity from stroke and is associated with increased mortality, this indicates the importance of routine ECG in patients with COPD.

The age-stratified comparison among COPD patients revealed age older than 60 years is significantly associated with more AF and right axis deviation in ECG and no other ECG abnormalities. These associations may be due to prolonged duration of disease when age increases and older age itself is a risk factor for AF but not $\mathrm{RVH}$. The presence of a S1-S2-S3 pattern was noted in $36 \%$ of the patients with COPD with a specificity of $60 \%$ for RVH in a study by Flowers and Horan, ${ }^{25}$ and they considered this pattern to be among the most reliable signs of RVH in their study.

All the abnormalities of ECG seen in our study which includes P-pulmonale, right axis deviation, RVH, RBBB and AF showed a uniformly increasing trend with the severity of GOLD stages. However, low-voltage ECG showing a mixed trend of developing low-voltage ECG with severity of GOLD. Disease duration at any stage of GOLD in almost all cases determines the severity of ECG. Again AF and right axis deviation in ECG had an increasing trend with the severity of smoking status. Similar study by Vij A et al. ${ }^{9}$ revealed that incidence of $\mathrm{P}$-pulmonale, rightward $\mathrm{QRS}$ axis deviation, right ventricular hypertrophy, RBBB, TR, right atrial enlargement and left ventricular diastolic dysfunction all increase with the longer duration of the disease.

\section{Conclusion}

The present study concludes that relatively more female preponderance is due to biomass exposure in this region of the country. The patient usually present in GOLD stage III at which various ECG changes are seen which indicate cardiac involvement due to COPD. Most of the diagnosis of ECG showed an increasing trend of abnormalities with the severity of COPD. The severity of the ECG changes increases with the duration of the disease and age of the patient except low voltage ECG, which is a non-specific findings. The AF is not an uncommon association in COPD and its frequency increases with smoking, disease duration, disease severity and age of the patient. A prospective longitudinal study with more number of patients will be more informative in this respect. 


\section{Disclosure}

The authors report no conflicts of interest in this work.

\section{Conflicts of Interest: None}

\section{References}

1. Lozano R, Naghavi M, Foreman $\mathrm{K}$ et al. Global and regional mortality from 235 causes of death for 20 age groups in 1990 and 2010: a systematic analysis for the Global Burden of Disease Study. Lancet 2012; 380(9859): 2095-2128.

2. Lee-Chiong TL, Matthay RA. The heart in the stable COPD patient. In: Similowski T, Whitelaw WA, Derenne JP, editors. Clinical Management of Chronic Obstructive Pulmonary Disease. New York: Marcel Dekker; 2002: 475-532.

3. Hunninghake D. Cardiovascular disease in chronic obstructive pulmonary disease. Proc Am ThoracSoc 2005; 2: 44-49.

4. Weitzenblum E, Hirth C, DucoloneA et al. Prognostic value of pulmonary artery pressure in chronic obstructive pulmonary disease. Thorax 1981; 36: 752-758.

5. Traver GA, Cline MG, Burrows B. Predictors of mortality in chronic obstructive pulmonary disease: a 15-year follow-up study. Am Rev Respir Dis 1979; 119: 895-902.

6. Sidney S, Sorel M, QuesenberryCPJr et al. COPD and incident cardiovascular disease hospitalizations and mortality: Kaiser Permanente Medical Care Program. Chest 2005; 128: 2068-2075.

7. Anthonisen NR, Connett JE, Kiley JP et al. Effects of smoking intervention and the use of an inhaled anticholinergic bronchodilator on the rate of decline of FEV1: The Lung Health Study. JAMA 1994; 272(19): 1497-1505.

8. Sin DD, Anthonisen NR, Soriano JB et al. Mortality in COPD: Role of comorbidities. EurRespir J 2006; 28: 1245-1257.

9. Vij A, Kapila S, Vij C et al. Study of Electrocardiographic and Echocardiographic Profile of COPD patients. JAPI 2008; 56: 290.

10. Van Durme YMTA, Verhamme KMC, Stijnen T et al. Prevalence, incidence, and lifetime risk for the development of COPD in the elderly: the Rotterdam study. Chest 2009; 135(2): 368-377.

11. Bischoff EW, Schermer TRJ, Bor HHJ et al. Trends in COPD prevalence and exacerbation rates in Dutch primary care. Br J Gen Pract 2009; 59(569): 927-933.

12. Geijer RM, Sachs AP, Hoes AW et al. Prevalence of undetected persistent airflow obstruction in male smokers 40-65 years old. FamPract 2005; 22(5): 485489.

13. Padmavati S, Raizada V. Electrocardiogram in chronic corpulmonale. Br Heart J 1972; 34: 658-667.
14. Spodick, DH. Electrocardiographic studies in pulmonary disease; II: establishment of criteria for the electrocardiographic influence of diffuse lung disease. Circulation 1959; 20: 1073-1074.

15. Chappell AG. The ECG in chronic bronchitis and emphysema. Br Heart J 1966; 28: 517.

16. Calatayud JB, Abod JM, Khoi NB et al. P wave changes in chronic obstructive pulmonary disease. Am Heart J 1970; 79: 444.

17. Caird Fl, Wilcken EL. The electrocardiogram in chronic bronchitis with generalized obstructive lung disease: Its relation to ventilatory function. $\mathrm{Am} \mathrm{J} \mathrm{Col} \mathrm{1962;}$ 10(1): 5-13.

18. Arilli DA, Denson $\sqcup$, Timmapuri N. Electrocardiographic Estimation of Pulmonary Impairment in Chronic Obstructive Lung Disease. Chest 1973; 63: 483-487.

19. Millard FJ. The electrocardiogram in chronic lung disease. Br Heart J 1967; 29: 43-50.

20. Milnor WR. The electrocardiogram and vectorcardiogram in right ventricular hypertrophy and right bundlebranch block. Circulation 1957; 16: 348-367.

21. Incalzi RA, Fuso L, Rosa MD et al. Co-morbidity contributes to predict mortality of patients with chronic obstructive pulmonary disease. EurRespir J 1997; 10: 2794-2800.

22. Dhar MC, Chaudhuri S, Pain S et al. Electrocardiographic Changes in Chronic corPulmonale with Chronic Obstructive Pulmonary Disease. JAPI 2002; 50.

23. Murphy ML, Hutcheson F. The Electrocardiographic Diagnosis of Right Ventricular Hypertrophy in Chronic Obstructive Pulmonary Disease. Chest 1974; 65: 622627.

24. Buch $\mathrm{P}$, Friberg J, Scharling $\mathrm{H}$ et al. Reduced lung function and risk of atrial fibrillation in The Copenhagen City Heart Study. EurRespir J 2003; 21: 1012-1016.

25. Flowers NC, Horan LG. Subtle signs of right ventricular enlargement and their relative importance. In:Schlant RD, Hurst JW, editors. Advances in Electrocardiography. New York: Grune and Stratton, Inc.; 1972. 297-308. 